OPEN ACCESS

Edited by:

Jianjun Xie,

Shantou University, China

Reviewed by:

Brian M. Olson,

Emory University, United States

Wang-Kai Fang,

Shantou University, China

*Correspondence:

Xiaobing Chen

chenxbxh@126.com

Specialty section:

This article was submitted to

Gastrointestinal Cancers,

a section of the journal

Frontiers in Oncology

Received: 04 July 2020 Accepted: 14 December 2020

Published: 01 February 2021

Citation:

Lv H, Zhang J, Sun K, Nie C, Chen B,

Wang J, Xu W, Wang S, Liu Y and Chen $X$ (2021) Expression of Human Epidermal Growth Factor Receptor-2

Status and Programmed Cell Death

Protein-1 Ligand Is Associated With

Prognosis in Gastric Cancer.

Front. Oncol. 10:580045.

doi: 10.3389/fonc. 2020.580045

\section{Expression of Human Epidermal Growth Factor Receptor-2 Status and Programmed Cell Death Protein-1 Ligand Is Associated With Prognosis in Gastric Cancer}

\author{
Huifang $L v^{1}$, Junling Zhang ${ }^{2}$, Keran Sun ${ }^{1}$, Caiyun Nie ${ }^{1}$, Beibei Chen ${ }^{1}$, Jianzheng Wang ${ }^{1}$, \\ Weifeng Xu ${ }^{1}$, Saiqi Wang ${ }^{1}$, Yingjun Liu $^{3}$ and Xiaobing Chen ${ }^{1 *}$ \\ 1 Department of Oncology, The Affiliated Cancer Hospital of Zhengzhou University, Henan Cancer Hospital, Zhengzhou, \\ China, ${ }^{2}$ Medical Department, 3D Medicines Inc., Shanghai, China, ${ }^{3}$ Department of Surgery, The Affiliated Cancer Hospital of \\ Zhengzhou University, Henan Cancer Hospital, Zhengzhou, China
}

Background: PD-L1 and HER-2 are routine biomarkers for gastric cancer (GC). However, little research has been done to investigate the correlation among PD-L1, HER-2, immune microenvironment, and clinical features in GC.

Methods: Between January 2013 and May 2020, a total of 120 GC patients treated with chemotherapy were admitted to Henan Tumor Hospital. We retrospectively identified PDL1, HER-2 level before chemotherapy and abstracted clinicopathologic features and treatment outcomes. Univariate and multivariate survival analyses were performed to assess the relationship between PD-L1/HER-2 levels and progression-free survival (PFS). The mRNA and tumor microenvironment of 343 patients with GC from The Cancer Genome Atlas (TCGA) were used to explore the underlying mechanism.

Results: We retrospectively analyzed 120 patients with gastric cancer, including 17 patients with HER-2 positive and 103 patients with HER-2 negative GC. The results showed that the expression of PD-L1 was closely correlated with HER-2 $(P=0.015)$. Patients with PD-L1/ HER-2 positive obtained lower PFS compared to PD-L1/HER-2 negative (mPFS: 6.4 vs. 11.1 months, $P=0.014$, mPFS: 5.3 vs. 11.1 months, $P=0.002$, respectively), and the PD-L1 negative and HER-2 negative had the best PFS than other groups $(P=0.0008)$. In a multivariate model, PD-L1 status, HER-2 status, tumor location, and tumor differentiation remained independent prognostic indicators for PFS $(P<0.05)$. The results of database further analysis showed that the proportion of PD-L1+/CD8A+ in HER-2 negative patients was higher than that in HER-2 positive patients (37.6 vs 20.3\%), while PD-L1-/CD8A- was significantly higher in HER-2 positive patients than HER-2 negative patients (57.8 vs. 28.8\%). In addition, it showed that not only CD4+T cells, macrophages, and CD8+T cells, but also the associated inflammatory pathways such as IFN- $\gamma /$ STAT1 were associated with HER-2.

Conclusion: HER-2 status could predict the efficacy of immune checkpoint inhibitors, and HER-2 status combined with PD-L1 level could predict the prognosis of GC patients.

Keywords: HER-2, PD-L1, prognosis, gastric cancer, CD8+T cells 


\section{INTRODUCTION}

Gastric cancer (GC) is a common malignant tumor in the digestive tract, ranking the second in the global mortality rate of malignant tumors, and more than $50 \%$ of new cases are from developing countries (1). The 5-year overall survival rate of metastatic GC is only $5-20 \%$ (2). Human epidermal growth factor receptor-2 (HER-2, also known as ERBB2) is a transmembrane receptor tyrosine kinase, and HER-2 expression is significantly upregulated in approximately $6-23 \%$ GC tissues (3-5). Since trastuzumab combined with chemotherapy became the standard treatment for advanced GC with positive HER-2 (ToGA study), a significant increase was needed for HER-2 assessment for GC (6). In breast cancer, HER-2 amplification and overexpression are associated with low prognosis, high mortality, and high recurrence and metastasis (7-9). However, the prognostic value of HER-2 in GC remains controversial. Some studies have shown that HER-2 positive patients have a high survival rate (10-12). In addition, HER-2 positive patients are correlated with serous membrane infiltration, lymph node metastasis, disease stage, distant metastasis, and other clinicopathological characteristics $(13,14)$. Other studies have shown no correlation between HER-2 expression and survival (15-17).

The interaction of programmed cell death protein-1 (PD-1) and its ligand (PD-L1) with immune cells and tumor cells limits the Tcell-mediated immune response (18). Immune checkpoint blocking of anti-PD-1 or anti-PD-L1 antibodies is the latest treatment for a variety of cancers, including non-small cell lung cancer (19-21), melanoma (22), bladder cancer (23), and kidney cancer (24). In early clinical studies, PD-1 inhibitors in the treatment of metastatic gastric cancer, such as pembrolizumab (25) and nivolumab (26), have been reported to have good efficacy. Current studies have shown that the expression level of PD-L1 in tumor tissue could be used to predict the efficacy of anti-PD-1 treatment (27); not only in patients with high expression of PD-L1 will it be effective, but also in patients with low expression of PD-L1. Therefore, it is essential to find the best biomarkers for GC in order to provide predictive information about the treatment response and ultimately improve the treatment outcome. The expression level of PD-L1 and the status of HER-2 are two important pathological characteristics of gastric cancer patients. Although some studies focused on the expression of PD-L1 and HER-2 in gastric cancer, the results of these studies are not consistent. Some researchers have found that expression of PD-L1, a potential biomarker for the immunotherapy response, was observed in HER-2 positive and negative patients to a similar extent, and its presence was not influenced by the HER-2 status (28). However, it has also been studied that the PD-L1 expression in GC is significantly correlated with HER2-negative status (29). Therefore, the relationship between HER-2 and PD-L1 state and what role the immune microenvironment plays in the prognosis of GC patients are still not clear.

In order to demonstrate the association between HER-2 and PD-L1 status, we analyzed the data from the largest available cohort of GC with both clinical and survival data. The immune microenvironment and PD-L1 mRNA from The Cancer Genome Atlas were also analyzed to explore the possible underlying mechanism.

\section{MATERIALS AND METHODS}

\section{Study Design and Clinical Data Collection}

We retrospectively reviewed 120 GC patients at the Affiliated Cancer Hospital of Zhengzhou University between January 2013 and May 2020. All patients were confirmed by two pathologists and the histological diagnoses were without discrepancy. Patients without any signs of distant metastasis preferably received neoadjuvant treatment, which was followed by surgical resection of the tumor. After an adjuvant chemotherapy period, routine control visits with computed tomography (CT) scans were performed. Patients with typical signs of distant metastasis underwent palliative chemotherapy. Biopsy or resection samples were used to detect $\mathrm{PD}-\mathrm{L} 1$ and HER-2 expression. If the tumor was HER-2 positive, trastuzumab was added to the treatment schedule. Trastuzumab was administered by intravenous infusion at a dose of $8 \mathrm{mg} / \mathrm{kg}$ on day 1 of the first cycle, followed by $6 \mathrm{mg} / \mathrm{kg}$ every 3 weeks until progression of the disease, the occurrence of unacceptable toxicity, or the patient's refusal. After administration of two cycles of chemotherapy or trastuzumab containing treatment, the size of the tumor was investigated by CT imaging and assessed using the Response Evaluation Criteria in Solid Tumors version 1.1 (RECIST 1.1). The following clinical characteristics were abstracted: age, sex, HER-2 status, PD-L1 status, tumor differentiation degree, lauren classification, treatment. The follow-up information was conducted via medical records plus telephone interview, and the following information was obtained: disease-free survival (DFS) and progression free survival (PFS).

In addition, the PD-L1 mRNA data and immune microenvironment of 343 patients with gastric cancer (GC) were sourced from The Cancer Genome Atlas (TCGA) (www. cbioportal.org).

The study was approved by relevant regulatory and independent ethics committee of the Henan Tumor Hospital and done in accordance with the Declaration of Helsinki and the International Conference on Harmonization Good Clinical Practice guidelines.

\section{Immunohistochemical Staining and Evaluation}

Representative sections of each surgical tumor resection or biopsy specimens were stained with PD-L1 antibody (SP263, Ventana) and VENTANA HER-2/neu rabbit monoclonal antibody (Clone 4B5, Ventana). Omission of primary antibody and substitution by nonspecific immunoglobins were used as negative controls. The immunoreactivity of PD-L1 was evaluated according to combined positive score (CPS). CPS was calculated by dividing the number of PD-L1 positive tumor cells, lymphocytes and histiocytes by the total number of vital tumor cells and then multiplying the result by 100 . Specimens in which PD-L1 staining was observed in CPS $>1$ were considered PD-L1 positive. And CPS $\leq 1$ was regarded as PD-L1 negative. IHC $3+$ or IHC $2+$ was defined as HER-2 positive.

\section{Fluorescence In Situ Hybridization}

When the result of IHC was 2+/3+, the amplification level of HER-2 was detected. PathVysion DNA Probe kit was used for 
the analysis of FISH according to the manufacturer's protocol. The positive results from FISH were defined as a HER-2: CEP17 ratio $\geq 2.0$. Examples of HER2 FISH positive and negative were shown in Figures 1E, F. According to the standards of the European Medicines Agency, HER-2 positive was defined as any case of IHC $3+$ or IHC $2+$ with a positive FISH result, while any case of IHC 0 , IHC $1+$ or IHC $2+$ with a negative FISH result is considered HER-2 negative.

\section{Statistical Analyses}

Progression free survival (PFS) was defined as the time from the date of first line therapy administration to the progression of cancer, or death from any cause. PFS was calculated using the Kaplan-Meier method. Correlation analyses were performed using the two-sided chi-squared test or the Fisher exact test.
Variables with significant $P$ values or interest were included into multivariate logistic regression. For all analyses, $P$ value $<0.05$ was considered to be statistically significant, and a confidence interval of $95 \%$ was used (95\% CI). All statistical analyses were performed using SPSS22.0 software (SPSS, Inc., Chicago, IL, USA).

\section{RESULTS}

\section{Patient Baseline Clinical Features}

We retrospectively analyzed 120 patients with gastric cancer in our hospital, including 17 patients with HER-2 positive and 103 patients with HER-2 negative GC (Table 1). There were 32 patients with PD-L1 positive and 88 patients with PD-L1
A

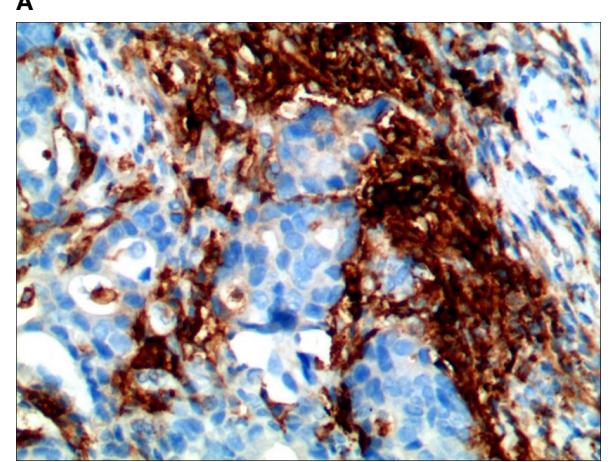

C

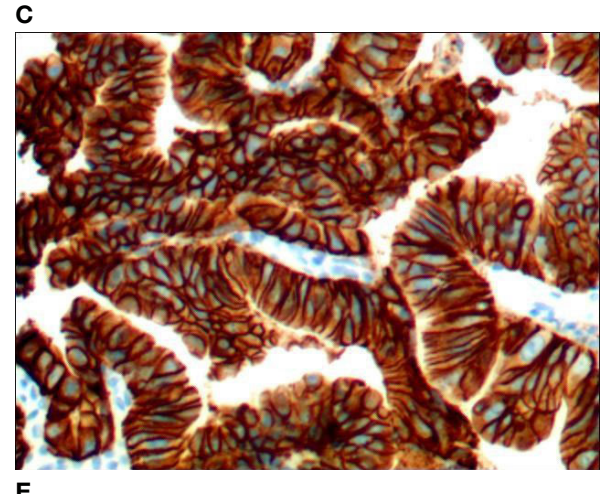

E

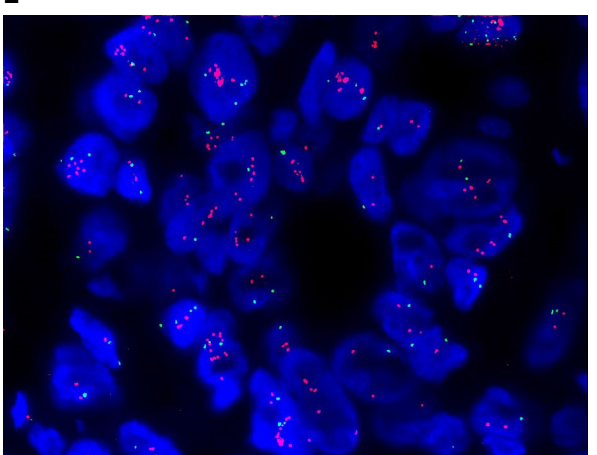

B

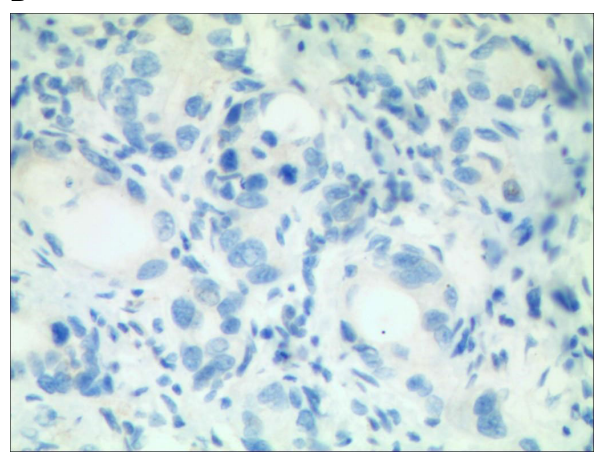

D

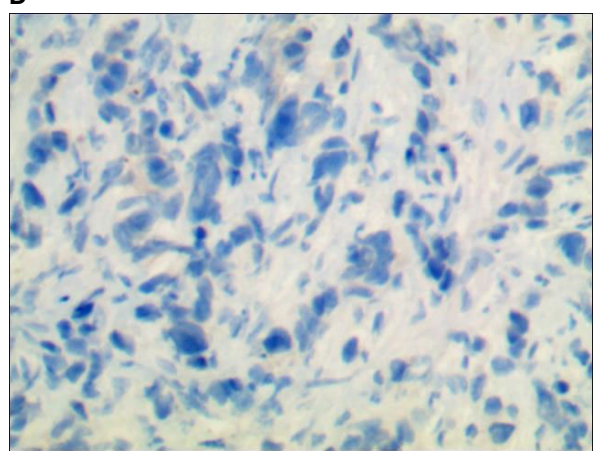

FIGURE 1 | Representative images of PD-L1 and HER-2 immunostaining/FISH results, (A) PD-L1 positive, (B) PD-L1 negative, (C) HER-2 positive by immunostaining, (D) HER-2 negative by immunostaining, (E) HER-2 positive by FISH. 
negative (Figure 1). $57.5 \%$ were male and $42.5 \%$ GC patients were $\geq 60$ years. The results showed that the expression of PD-L1 was closely correlated with HER-2 status, with statistical significance $(P=0.015$, as shown in Table 1$)$.

\section{Association Between Programmed Cell Death Protein-1 Ligand/Human Epidermal Growth Factor Receptor-2 Status and Survival Outcomes}

We analyzed whether PD-L1/HER-2 status was associated with the survival outcomes of chemotherapy in advanced GC. Patients with PD-L1 positive obtained lower PFS compared to PD-L1 negative (mPFS: 6.4 vs. 11.1 months, $P=0.014$, Figure 2A). The similar results were in HER-2 negative (mPFS: 5.3 vs. 11.1 months, $P=$ 0.002 , Figure 2B). And the PD-L1 negative and HER-2 negative had the best PFS than the other groups $(P=0.0008$, Figure 2C). In the present study, univariable analysis revealed significant association

TABLE 1 | Clinicopathologic and baseline clinical features of gastric cancer patients.

\begin{tabular}{|c|c|c|c|}
\hline Characteristics & $\begin{array}{l}\text { PD-L1 Positive } \\
\qquad(n=32)\end{array}$ & $\begin{array}{l}\text { PD-L1 Negative } \\
\text { (n =88) }\end{array}$ & $P$ \\
\hline \multicolumn{4}{|l|}{ Sex } \\
\hline Male & 21 & 48 & \multirow[t]{2}{*}{0.3039} \\
\hline Female & 11 & 40 & \\
\hline \multicolumn{4}{|l|}{ Age } \\
\hline$\geq 60$ & 14 & 37 & \multirow[t]{2}{*}{$>0.9999$} \\
\hline$<60$ & 18 & 51 & \\
\hline \multicolumn{4}{|c|}{ Histological differentiation } \\
\hline Moderate & 7 & 17 & \multirow[t]{3}{*}{0.7031} \\
\hline Poor & 19 & 48 & \\
\hline NOS & 6 & 23 & \\
\hline \multicolumn{4}{|l|}{ Lauren Classification } \\
\hline Diffuse & 4 & 18 & \multirow[t]{4}{*}{0.1809} \\
\hline Intestinal & 2 & 8 & \\
\hline Mixed & 5 & 4 & \\
\hline Unknown & 21 & 58 & \\
\hline \multicolumn{4}{|l|}{ Tumor Location } \\
\hline Body & 12 & 31 & \multirow[t]{4}{*}{0.2573} \\
\hline Antrum & 5 & 11 & \\
\hline Cardia, gastric fundus & 15 & 36 & \\
\hline Unknown & 0 & 10 & \\
\hline \multicolumn{4}{|l|}{ T stage (\%) } \\
\hline $\mathrm{T} 1$ & 0 & 4 & \multirow[t]{5}{*}{0.336} \\
\hline T2 & 4 & 7 & \\
\hline T3 & 7 & 30 & \\
\hline T4 & 6 & 9 & \\
\hline Tx & 15 & 38 & \\
\hline \multicolumn{4}{|l|}{ N stage (\%) } \\
\hline NO & 4 & 13 & \multirow[t]{5}{*}{0.8118} \\
\hline N1 & 2 & 6 & \\
\hline N2 & 2 & 12 & \\
\hline N3 & 8 & 18 & \\
\hline $\mathrm{Nx}$ & 16 & 39 & \\
\hline \multicolumn{4}{|l|}{ M stage (\%) } \\
\hline $\mathrm{MO}$ & 15 & 54 & \multirow[t]{3}{*}{0.1476} \\
\hline M1 & 17 & 31 & \\
\hline $\mathrm{Mx}$ & 0 & 3 & \\
\hline \multicolumn{4}{|l|}{ HER-2 status } \\
\hline Positive. & 9 & 8 & \multirow[t]{2}{*}{0.0153} \\
\hline Negative & 23 & 80 & \\
\hline
\end{tabular}

between poorer PFS and PD-L1 status, HER-2 status, tumor location in body, while there was no relation between PFS and age, sex, lauren classification and tumor differentiation (Table 2). In a multivariate model, PD-L1 status, HER-2 status, tumor location, and tumor differentiation remained independent prognostic indicators for PFS (Table 1, $P<0.05$ ).

\section{Association Between Human Epidermal Growth Factor Receptor-2 Status and Programmed Cell Death Protein-1 Ligand mRNA Expression}

In order to explore the mechanism of potential, we first analyzed whether HER-2 status was associated with the PD-L1 mRNA expression in GC. It showed that the expression of PD-L1 was higher in HER-2 negative GC, but decreased in HER-2 positive GC (Figure 3, $P<0.0001$ ).

\section{Association Between Programmed Cell Death Protein-1 Ligand Status and Tumor-Infiltrating Lymphocyte}

tAccording to the classification of PD-L1 and TIL, tumors were divided into $\mathrm{PD}-\mathrm{L}^{-} / \mathrm{TIL}^{-}, \mathrm{PD}-\mathrm{L}^{+} / \mathrm{TIL}^{+}, \mathrm{PD}-\mathrm{Ll}^{+} / \mathrm{TIL}^{-}$and $\mathrm{PD}-$ $\mathrm{L}^{-} / \mathrm{TIL}^{+}$, among which $\mathrm{PD}-\mathrm{Ll}^{+} / \mathrm{TIL}^{+}$was considered to be the most suitable state for immunotherapy (27). We further analyzed the effect of HER-2 on the distribution of PD-L1/CD8A in TCGA data. In HER-2 amplified patients, the proportions of $\mathrm{PD}-\mathrm{Ll}^{+} /$ $\mathrm{CD}^{+} A^{+}, \mathrm{PD}-\mathrm{L1}^{+} / \mathrm{CD}^{-} \mathrm{A}^{-}, \mathrm{PD}-\mathrm{L1}^{-} / \mathrm{CD} \mathrm{A}^{+}$and $\mathrm{PD}-\mathrm{L} 1^{-} / \mathrm{CD} 8 \mathrm{~A}^{-}$ were $20.3,12.5,15.6$, and $57.8 \%$, respectively. The proportions of $\mathrm{PD}-\mathrm{L}^{+} / \mathrm{CD} \mathrm{A}^{+}, \mathrm{PD}-\mathrm{Ll}^{+} / \mathrm{CD} 8 A^{-}, \mathrm{PD}-\mathrm{L}^{-} / \mathrm{CD} 8 A^{+}$, and $\mathrm{PD}-\mathrm{Ll}^{-} /$ $\mathrm{CD}^{-} \mathrm{A}^{-}$in patients without HER-2 amplification were 37.6, 16.4, 17.2, and 28.8\%, respectively (see Figure 4, $P<0.001$ ). The results indicated that the ratio of $\mathrm{PD}-\mathrm{L}^{+} / \mathrm{CD} 8 \mathrm{~A}^{+}$was significantly increased in patients without HER-2 amplification, while the ratio of $\mathrm{PD}-\mathrm{L1}^{-} / \mathrm{CD} 8 \mathrm{~A}^{-}$was the highest in patients with HER-2 amplification. This result further suggests that immunotherapy may be more effective for patients with HER2-negative GC, while patients with HER2-positive GC have a poorer prognosis, and combination therapy may be effective.

\section{Association Between Human Epidermal Growth Factor Receptor-2 Status and Immune Cell Infiltration}

In the following experiments, we attempted to explore the effect of HER-2 status on immune cell infiltration. Through deconvolution of 574 labeled gene expression values, the proportions of 22 kinds of immune cells in GC tissues in TCGA database were analyzed by CIBERSORT. The results showed that the proportion of resting state memory CD4+ $\mathrm{T}$ cells was the highest in GC samples, followed by macrophages. CD8+ T cells and memory B cells were highly expressed in the non-amplified HER-2 group, while resting state memory CD4+ $\mathrm{T}$ cells and M0 macrophages were highly expressed in the amplified HER-2 group (Figures 5A, B).

Pearson correlation analysis showed that there was no significant correlation among immune cells infiltration (Figure 5B). M1-type 


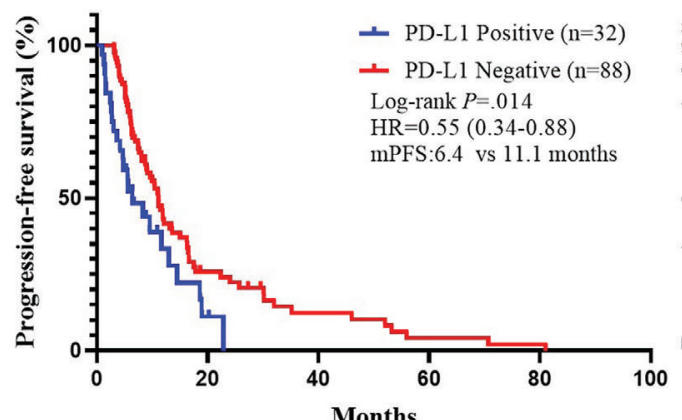

C

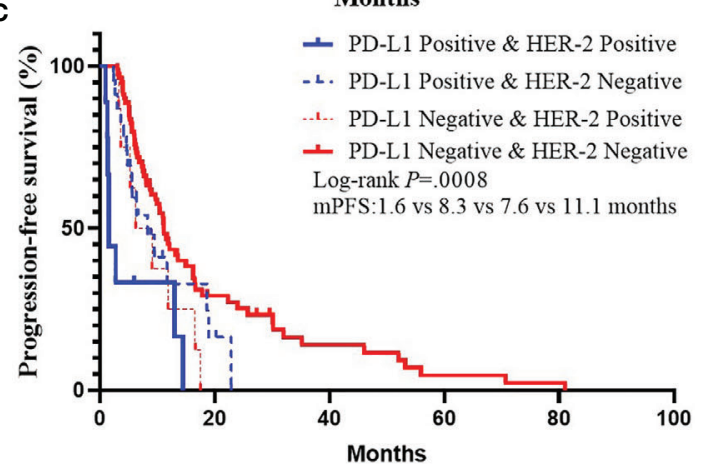

B

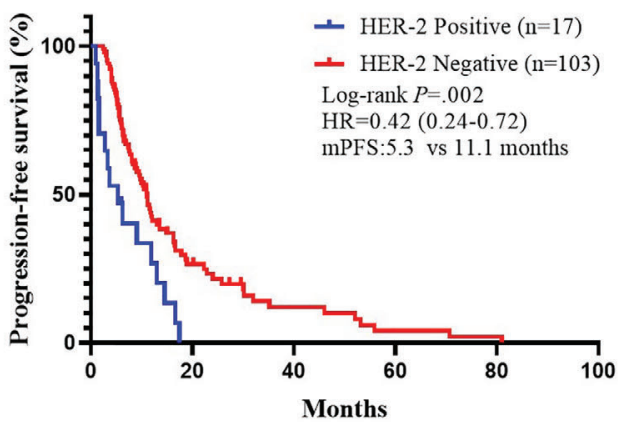

- HER-2 Negative $(\mathrm{n}=103)$

$\mathrm{HR}=0.42(0.24-0.72)$

mPFS:5.3 vs 11.1 months

FIGURE 2 | Kaplan-Meier Estimates of Progression-Free Survival by PD-L1 Status or HER-2 status. (A) Kaplan-Meier survival curves of PFS by PD-L1 status. (B) Kaplan-Meier survival curves of PFS by HER-2 status. (C) Kaplan-Meier survival curves of PFS by PD-L1 and HER-2 status.

TABLE 2 | Univariate and multivariate analyses of progression-free survival.

\begin{tabular}{|c|c|c|c|c|c|c|}
\hline Parameter & \multicolumn{3}{|c|}{ Univariate analysis } & \multicolumn{3}{|c|}{ Multivariate analysis } \\
\hline $\begin{array}{l}\text { Sex } \\
\text { Male vs Female }\end{array}$ & 0.769 & $0.509-1.162$ & 0.213 & & & \\
\hline $\begin{array}{l}\text { Age } \\
\qquad 660 v s<60\end{array}$ & 0.825 & $0.540-1.260$ & 0.373 & & & \\
\hline $\begin{array}{l}\text { Tumor differentiation } \\
\text { Moderate vs. poorly }\end{array}$ & 0.629 & $0.375-1.056$ & 0.080 & 0.444 & $0.25-0.777$ & 0.004 \\
\hline $\begin{array}{l}\text { Tumor location } \\
\text { Body vs antrum }\end{array}$ & 1.614 & $1.034-2.519$ & 0.035 & & & \\
\hline $\begin{array}{l}\text { PD-L1 status } \\
\text { Negative vs Positive }\end{array}$ & 0.547 & $0.339-0.883$ & 0.014 & 0.596 & $0.364-0.975$ & 0.039 \\
\hline $\begin{array}{l}\text { HER-2 status } \\
\text { Negative vs Positive }\end{array}$ & 0.416 & $0.240-0.722$ & 0.002 & 0.280 & $0.149-0.525$ & 0.000 \\
\hline
\end{tabular}

macrophages were moderately correlated with activated memory CD4+ T cells $(r=0.41)$, while resting memory CD $4+\mathrm{T}$ cells were negatively correlated with $\mathrm{CD} 8+\mathrm{T}$ cells $(\mathrm{r}=-0.41)$. The results showed that the proportion of resting CD4+ T cells in the immune microenvironment of HER-2 amplified patients was high, and the proportion of activated memory CD4+ T cells was low, suggesting that $\mathrm{CD} 4+\mathrm{T}$ cells in the immune microenvironment were not activated, which reduced the flooding effect of CD8+ T cells in the immune microenvironment, leading to decreased infiltration of CD8+ T cells.

\section{Association Between Human Epidermal Growth Factor Receptor-2 Status and Cytokines}

By comparing HER-2 amplification and non-amplification groups, significant changes in some cytokines were found as 


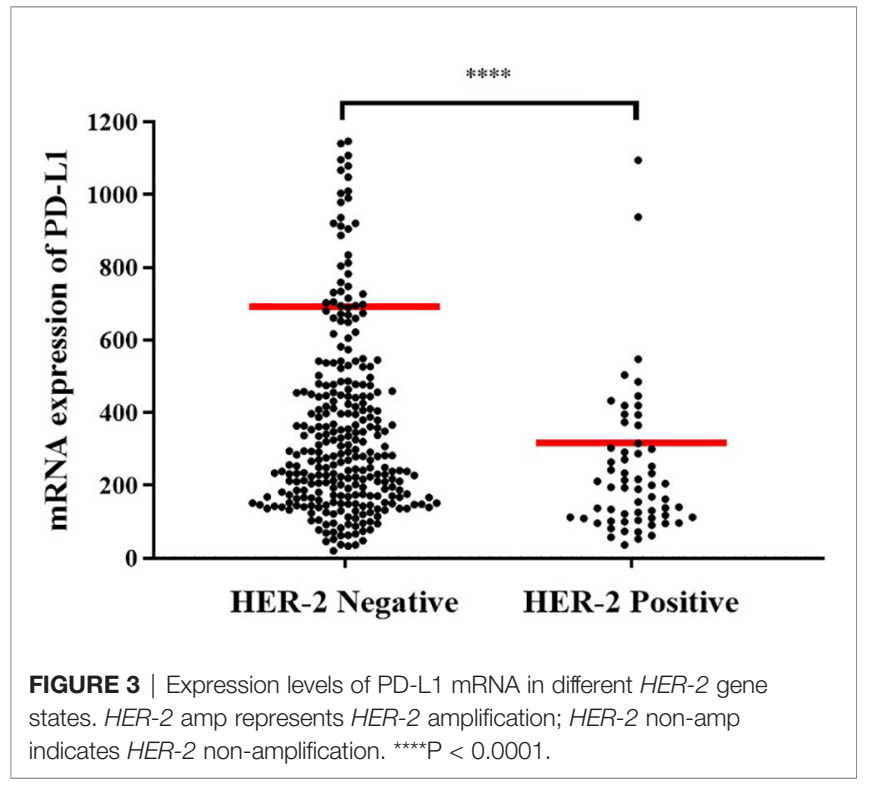

shown in Figure 6A, and INF- $\gamma$ was significantly decreased. By using an online system (https://string-db.org/cgi/network.pl? taskId=lP6ij62YlPsZ), we found that the STAT1 had a close reciprocal relationship with $I F N-\gamma$. Biological process analysis of cytokines showed that they are mainly involved in immune responsibility-related reactions (Figure 6B). At the same time, KEGG pathway analysis was also carried out, and it was found that antigen processing and presentation, natural killer cell

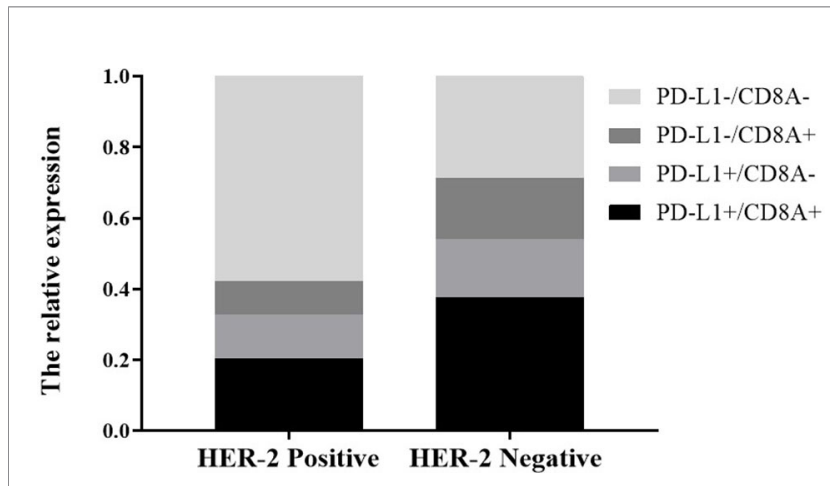

FIGURE 4 | Effect of HER-2 status on tumor immune typing.

mediated cytotoxicity and Toll-like receptor signaling pathway were included (Figure 6D). Therefore, we could find that HER-2 status is closely related to the immune response. Amplification of HER-2 may negatively regulate the immune response of GC and further affect the anti-tumor effect, which explains why immunotherapy for HER-2 positive GC patients is not effective.

\section{DISCUSSION}

As immunotherapy has ushered in a new era in the treatment of GC, PD-1 inhibitors have become the standard treatment for PD-L1 positive advanced GC, and further studies on immune-
A

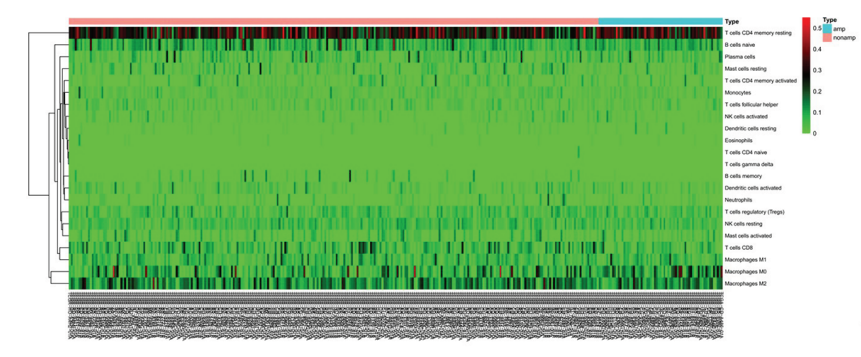

B

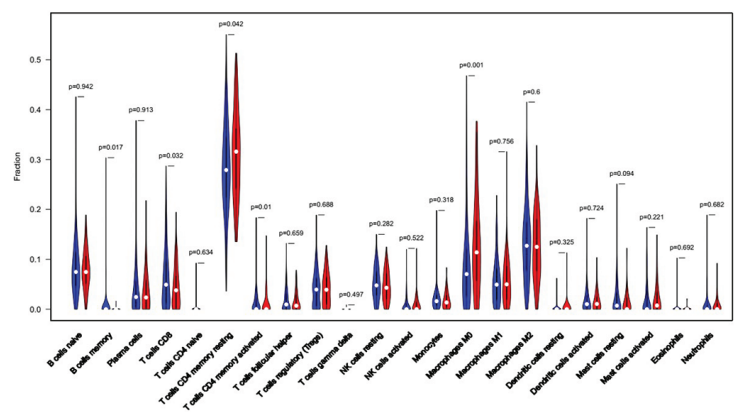$$
\text { (n) }
$$

C

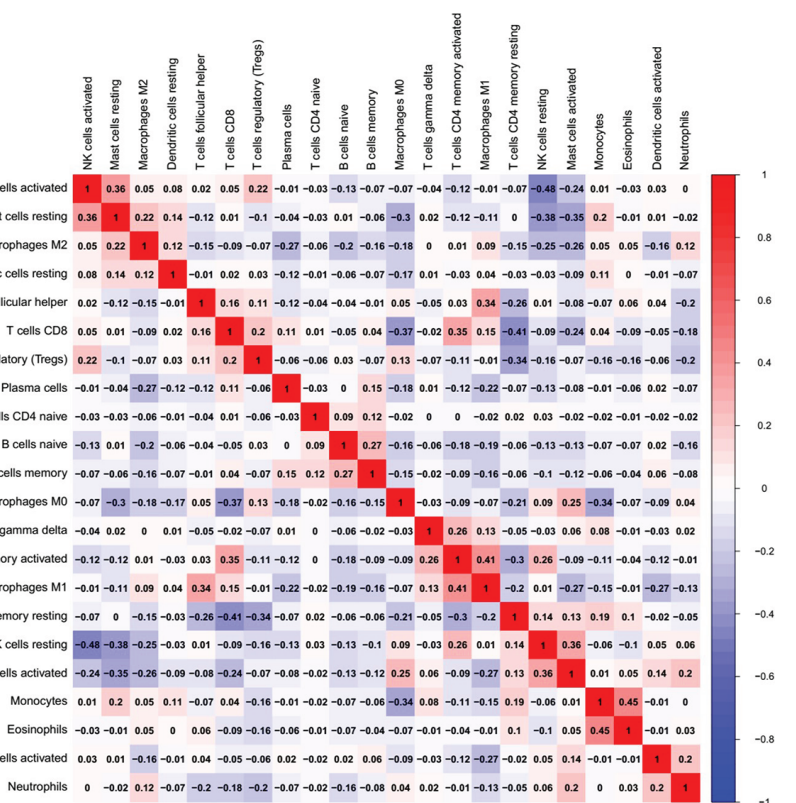

FIGURE 5 | Effects of HER-2 status and immune cell infiltration. (A) The heat map of immune cells in GC. (B) The proportion of 22 immune cells in GC. (C) The correlation between the immune cells infiltration in GC by Pearson analyzed. 


\section{A}
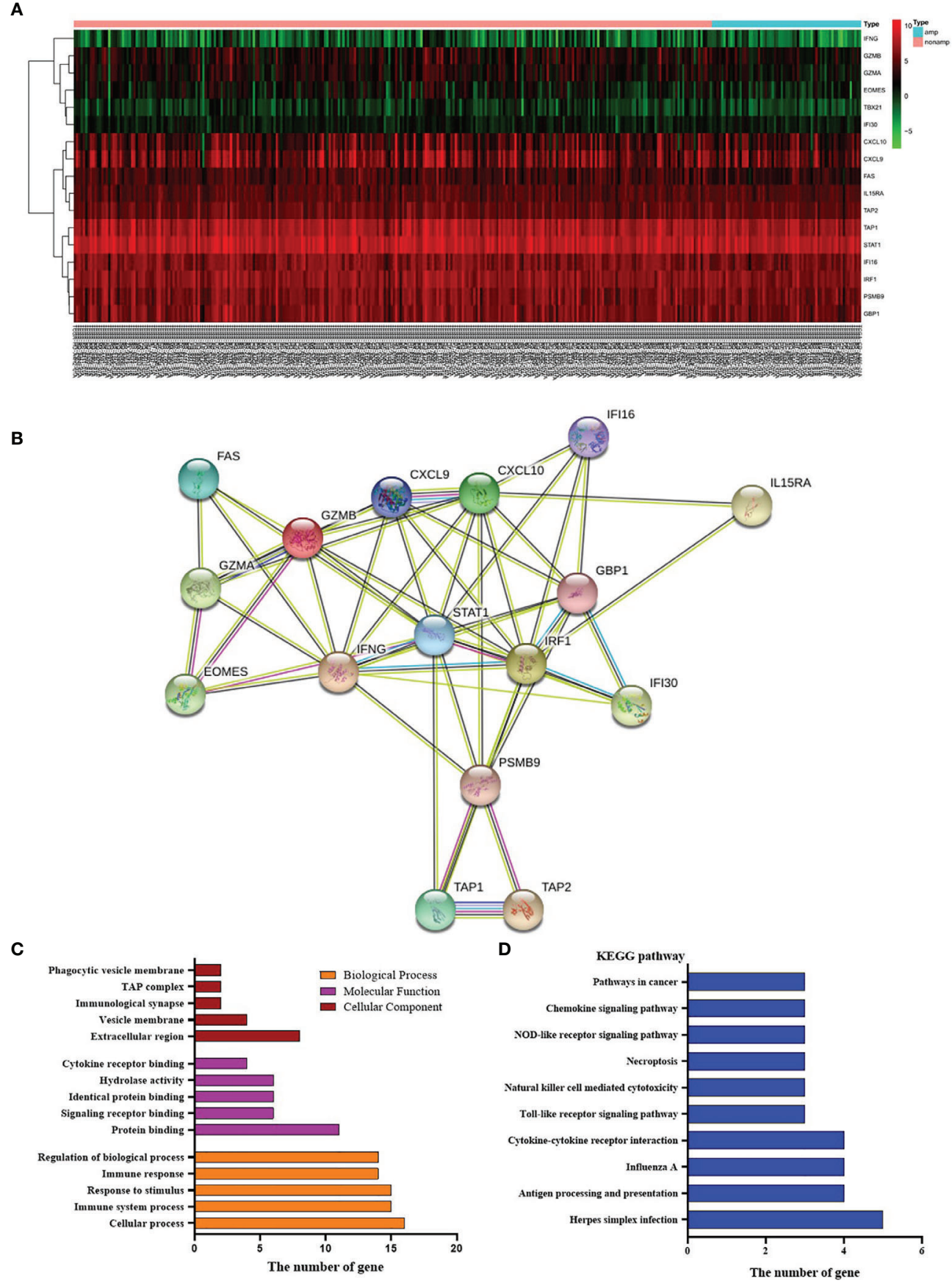

FIGURE 6 | Effects of HER-2 status and cytokines. (A) The heat map of cytokines in GC. (B) Interaction mapping of different gene in HER-2 Amp and non-amp group. (C) Gene distribution based on GO analysis. (D) KEGG pathway analysis of differential genes.

related biomarkers and their interactions with other cancerrelated pathways are necessary. In our study, we investigated the potential correlation between HER-2 and PD-L1 expression and their relationship with clinical characteristics and prognosis in patients with GC.

Immunotherapy, especially immune checkpoint blockade, has become a promising cancer treatment. Immune checkpoint inhibitors, such as anti-PD-1 and anti-PD-L1, have been approved by the Food and Drug Administration (FDA) for the treatment of various types of cancer, resulting in durable tumor regression and prolonged survival $(30,31)$. It has also been shown that blocking PD-L1 could improve the immune function of tumor-specific effector T cells when interacting with target tumor cells in vitro (32). However, the relationship 
between PD-L1 expression and prognosis in GC is still controversial. Some studies found that the prognosis of GC patients with PD-L1 positive was significantly improved (33). On the contrary, other researchers have shown that high PD-L1 expression was a significant poor prognostic factor (34). In this study, we found that positive PD-L1 in GC tissues was associated with poor prognosis of PFS. This finding is consistent with previous research results (35). A reasonable hypothesis for the poor clinical efficacy of $\mathrm{PD}-\mathrm{L} 1$ positive tumors is that the up-regulation of PD-L1 in immune cells inactivates cytotoxic T lymphocytes (CTLs), leading to host immune evasion.

Interestingly, we also found that the expression of PD-L1 was higher in HER-2 negative GC, but decreased in HER-2 positive GC which might lead to a novel treatment strategy. As in the ToGA study, only HER-2 positive patients can benefit from antiHER-2 drug (5). Anti-PD-1/PD-L1 immunotherapy might become a potentially new treatment for HER-2 negative patients. Whether HER-2 could be used independently as an indicator to evaluate the disease progression and prognosis of GC patients was still a big controversy. A retrospective study found that HER-2 was highly expressed in GC and closely related to poor quality of life and short survival, indicating that HER-2 has a certain potential value in prognosis assessment of GC (12). Other research results showed that the high expression of HER-2 in GC tissues was only negatively correlated with the degree of tumor differentiation, while there was no difference in the distribution of other pathological characteristics related data such as gender, age, tumor size (36), which were similarly with our study.

More literature indicates that tumor microenvironment plays a critical role in cancer progression and treatment response (37). Not only compositions, but also the number of T cells, associated macrophages, and associated inflammatory pathways influenced the immune response and chemotherapy benefit at diagnosis (38-40). Based on the existence of tumor-infiltrating lymphocytes (TILs) and PD-L1 expression, we know that PD-L1+CD8+ was adaptive immune resistance. In our study, the ratio of $\mathrm{PD}-\mathrm{L} 1+/ \mathrm{CD} 8 \mathrm{~A}+$, CD8+T cells, and B cells were highly expressed in the nonamplified HER-2 group and CD4+T cells and macrophages M0 were highly expressed in the amplified HER-2 group. In addition, immune responsibility-related reactions of biological process and a significant decrease in IFN- $\gamma$ were found in HER- 2 negative GC. Those also highlight the potential role of tumor microenvironment

\section{REFERENCES}

1. Torre LA, Bray F, Siegel RL, Ferlay J, Lortet-Tieulent J, Jemal A. Global Cancer Statistics 2012. CA Cancer J Clin (2015) 65(2):87-108. doi: 10.3322/caac.21262

2. Wagner AD, Syn NL, Moehler M, Grothe W, Yong WP, Tai B-C, et al. Chemotherapy for advanced gastric cancer. Cochrane Database Syst Rev (2017) 8(29):CD004064. doi: 10.1002/14651858.CD004064.pub4

3. Hsu J-T, Chen T-C, Tseng J-H, Chiu C-T, Liu K-H, Yeh C-N, et al. Impact of HER-2 overexpression/amplification on the prognosis of gastric cancer patients undergoing resection: a single-center study of 1,036 patients. Oncologist (2011) 16(12):1706-13. doi: 10.1634/theoncologist.2011-0199 in GC and explain the fact that HER-2 negative patients are more suitable for immunotherapy.

Taken together, PD-L1 positive in tumor cells is correlated with worse prognosis in GC patients and is correlated positively with HER-2 positive. Our findings suggest that tumors expressing higher levels of PD-L1 are more aggressive and that administration of adjuvant chemotherapy should be considered for patients with these tumors.

\section{DATA AVAILABILITY STATEMENT}

The original contributions presented in the study are included in the article/supplementary material, further inquiries can be directed to the corresponding author.

\section{ETHICS STATEMENT}

The study was approved by relevant regulatory and independent ethics committee of the Henan Tumor Hospital and done in accordance with the Declaration of Helsinki.

\section{AUTHOR CONTRIBUTIONS}

HL and XC designed the study. HL and JZ wrote the first draft of the manuscript. HL, KS, CN, BC, JW, WX, SW, and YL treated the patients and acquired data. HL and JZ analyzed the data. XC revised the manuscript. All authors contributed to the article and approved the submitted version.

\section{FUNDING}

We would like to thank the financial support from the National Natural Science Foundation of China (No. 81472714), 1000 Talents Program of Central plains (No. 204200510023), Science and Technique Foundation of Henan Province (No. 202102310413), Medical Science and Technique Foundation of Henan Province (Nos. 2018020486 and SB201901101) and State Key Laboratory of Esophageal Cancer Prevention \& Treatment (No. Z2020000X).
4. Sheng WQ, Huang D, Ying JM, Lu N, Wu HM, Liu YH, et al. HER2 status in gastric cancers: a retrospective analysis from four Chinese representative clinical centers and assessment of its prognostic significance. Ann Oncol (2013) 24(9):2360-4. doi: 10.1093/annonc/mdt232

5. Bang YJ, Van Cutsem E, Feyereislova A, Chung HC, Shen L, Sawaki A, et al. Trastuzumab in combination with chemotherapy versus chemotherapy alone for treatment of HER2-positive advanced gastric or gastro-oesophageal junction cancer (ToGA): a phase 3, open-label, randomised controlled trial. Lancet (2010) 376(9742):687-97. doi: 10.1016/S0140-6736(10)61121-X

6. Kai K, Yoda Y, Kawaguchi A, Minesaki A, Iwasaki H, Aishima S, et al. Formalin fixation on HER-2 and PD-L1 expression in gastric cancer: A pilot 
analysis using the same surgical specimens with different fixation times. World J Clin Cases (2019) 7(4):419-30. doi: 10.12998/wjcc.v7.i4.419

7. Seshadri R, Horsfall DJ, Firgaira F, McCaul K, Setlur V, Chalmers AH, et al. The relative prognostic significance of total cathepsin D and HER-2/neu oncogene amplification in breast cancer. The South Australian Breast Cancer Study Group. Int J Cancer (1994) 56(1):61-5. doi: 10.1002/ijc.2910560112

8. Slamon DJ, Clark GM, Wong SG, Levin WJ, Ullrich A, McGuire WL. Human breast cancer: correlation of relapse and survival with amplification of the HER-2/neu oncogene. Science (1987) 235(4785):177-82. doi: 10.1126/ science. 3798106

9. Toikkanen S, Helin H, Isola J, Joensuu H. Prognostic significance of HER-2 oncoprotein expression in breast cancer: a 30-year follow-up. J Clin Oncol (1992) 10(7):1044-8. doi: 10.1200/JCO.1992.10.7.1044

10. Gómez-Martin C, Garralda E, Echarri MJ, Ballesteros A, Arcediano A, Rodríguez-Peralto JL, et al. HER2/neu testing for antiHER2-based therapies in patients with unresectable and/or metastatic gastric cancer. J Clin Pathol (2012) 65(8):751-7. doi: 10.1136/jclinpath-2012-200774

11. Jain S, Filipe MI, Gullick WJ, Linehan J, Morris RW. c-erbB-2 proto-oncogene expression and its relationship to survival in gastric carcinoma: an immunohistochemical study on archival material. Int J Cancer (1991) 48 (5):668-71. doi: 10.1002/ijc.2910480506

12. Jorgensen JT, Hersom M. HER2 as a prognostic marker in gastric cancer-a systematic analysis of data from the literature. J Cancer (2012) 3(0):137-44. doi: $10.7150 /$ jca.4090

13. Qiu M-Z, Li Q, Wang Z-Q, Liu T-S, Liu Q, Wei X-L, et al. HER2-positive patients receiving trastuzumab treatment have a comparable prognosis with HER2-negative advanced gastric cancer patients: a prospective cohort observation. Int J Cancer (2014) 134(10):2468-77. doi: 10.1002/ijc.28559

14. Liang J-W, Zhang J-J, Zhang T, Zheng Z-C. Clinicopathological and prognostic significance of HER2 overexpression in gastric cancer: a meta-analysis of the literature. Tumour Biol (2014) 35(5):4849-58. doi: 10.1007/s13277-014-1636-3

15. He C, Bian X-Y, Ni X-Z, Shen D-P, Shen Y-Y, Liu H, et al. Correlation of human epidermal growth factor receptor 2 expression with clinicopathological characteristics and prognosis in gastric cancer. World J Gastroenterol (2013) 19(14):2171-8. doi: 10.3748/wjg.v19.i14.2171

16. Janjigian YY, Werner D, Pauligk C, Steinmetz K, Kelsen DP, Jäger E, et al. Prognosis of metastatic gastric and gastroesophageal junction cancer by HER2 status: a European and USA Internationalcollaborative analysis. Ann Oncol (2012) 23(10):2656-62. doi: 10.1093/annonc/mds104

17. Kataoka Y, Okabe H, Yoshizawa A, Minamiguchi S, Yoshimura K, Haga H, et al. HER2 expression and its clinicopathological features in resectable gastric cancer. Gastric Cancer (2013) 16(1):84-93. doi: 10.1007/s10120-012-0150-9

18. Topalian SL, Drake CG, Pardoll DM. Targeting the PD-1/B7-H1 (PD-L1) pathway to activate anti-tumor immunity. Curr Opin Immunol (2012) 24 (2):207-12. doi: 10.1016/j.coi.2011.12.009

19. Garon EB, Rizvi NA, Hui R, Leighl N, Balmanoukian AS, Eder JP, et al. Pembrolizumab for the treatment of non-small-cell lung cancer. N Engl J Med (2015) 372(372):2018-28. doi: 10.1056/NEJMoa1501824

20. Antonia S, Goldberg SB, Balmanoukian A, Chaft JE, Sanborn RE, Gupta A, et al. Safety and antitumour activity of durvalumab plus tremelimumab in non-small cell lung cancer: a multicentre, phase $1 \mathrm{~b}$ study. Lancet Oncol (2016) 17(3):299-308. doi: 10.1016/S1470-2045(15)00544-6

21. Borghaei H, Paz-Ares L, Horn L, Spigel DR, Steins M, Ready NE, et al. Nivolumab versus docetaxel in advanced nonsquamous non-small-cell lung cancer. N Engl J Med (2015) 373(17):1627-39. doi: 10.1056/NEJMoa1507643

22. Weber JS, D’Angelo SP, Minor D, Hodi FS, Gutzmer R, Neyns B, et al. Nivolumab versus chemotherapy in patients with advanced melanoma who progressed after anti-CTLA-4 treatment (CheckMate 037): a randomised, controlled, open-label, phase 3 trial. Lancet Oncol (2015) 16(4):375-84. doi: 10.1016/S1470-2045(15)70076-8

23. Powles T, Eder JP, Fine GD, Braiteh FS, Loriot Y, Cruz C, et al. MPDL3280A (anti-PD-L1) treatment leads to clinical activity in metastatic bladder cancer. Nature (2014) 515(7528):558-62. doi: 10.1038/nature13904

24. McDermott DF, Drake CG, Sznol M, Choueiri TK, Powderly JD, Smith DC, et al. Survival, Durable Response, and Long-Term Safety in Patients With Previously Treated Advanced Renal Cell Carcinoma Receiving Nivolumab. J Clin Oncol (2015) 33(18):2013-20. doi: 10.1200/JCO.2014.58.1041
25. Muro K, Chung HC, Shankaran V, Geva R, Catenacci D, Gupta S, et al. Pembrolizumab for patients with PD-L1-positive advanced gastric cancer (KEYNOTE-012): a multicentre, open-label, phase $1 \mathrm{~b}$ trial. Lancet Oncol (2016) 17(6):717-26. doi: 10.1016/S1470-2045(16)00175-3

26. Kang YK. Nivolumab (ONO-4538/BMS-936558) as salvage treatment after second or later-line chemotherapy for advanced gastric or gastro-esophageal junction cancer (AGC): A double-blinded, randomized, phase III trial. J Clin Oncol (2017) 35(4_suppl):2-2. doi: 10.1200/JCO.2017.35.4_suppl.2

27. Sanmamed MF. Chen L. A Paradigm Shift in Cancer Immunotherapy: From Enhancement to Normalization. Cell (2018) 175(2):313-26. doi: 10.1016/ j.cell.2018.09.035

28. Beer A, Taghizadeh H, Schiefer AI, Puhr HC, Karner AK, Jomrich G, et al. PD-L1 and HER2 Expression in Gastroesophageal Cancer: a Matched Case Control Study. Pathol Oncol Res (2020) 26(4):2225-35. doi: 10.1007/s12253020-00814-2

29. Wang L, Zhang Q, Ni S, Tan C, Cai X, Huang D, et al. Programmed deathligand 1 expression in gastric cancer: correlation with mismatch repair deficiency and HER2-negative status. Cancer Med (2018) 7(6):2612-20. doi: 10.1002/cam4.1502

30. Choueiri TK, Fishman MN, Escudier B, McDermott DF, Drake CG, Kluger H, et al. Immunomodulatory Activity of Nivolumab in Metastatic Renal Cell Carcinoma. Clin Cancer Res (2016) 22(22):5461-71. doi: 10.1158/10780432.CCR-15-2839

31. Pardoll DM. The blockade of immune checkpoints in cancer immunotherapy. Nat Rev Cancer (2012) 12(4):252-64. doi: 10.1038/nrc3239

32. Blank C, Kuball J, Voelkl S, Wiendl H, Becker B, Walter B, et al. Blockade of PD-L1 (B7-H1) augments human tumor-specific T cell responses in vitro. Int J Cancer (2006) 119(2):317-27. doi: 10.1002/ijc.21775

33. Boger C, Behrens HM, Mathiak M, Kruger S, Kalthoff H, Rocken C. PD-L1 is an independent prognostic predictor in gastric cancer of Western patients. Oncotarget (2016) 7(17):24269-83. doi: 10.18632/oncotarget.8169

34. Chang H, Jung WY, Kang Y, Lee H, Kim A, Kim HK, et al. Programmed death-ligand 1 expression in gastric adenocarcinoma is a poor prognostic factor in a high $\mathrm{CD} 8+$ tumor infiltrating lymphocytes group. Oncotarget (2016) 7(49):80426-34. doi: 10.18632/oncotarget.12603

35. Gu L, Chen M, Guo D, Zhu H, Zhang W, Pan J, et al. PD-L1 and gastric cancer prognosis: A systematic review and meta-analysis. PloS One (2017) 12(8): e0182692. doi: 10.1371/journal.pone.0182692

36. Zhao LN, Zhao HB, Wang Q, Li QZ, Yin TT. Correlation of HER2 and PD-L1 Expression in the Gastric Cancer Tissues with the Clinicopathological Features. Prog Modern Biomed (2019) 19:4324-400. doi: 10.13241/ j.cnki.pmb.2019.22.027

37. Jiang Y, Zhang Q, Hu Y, Li T, Yu J, Zhao L, et al. ImmunoScore signature: a prognostic and predictive tool in gastric cancer. Ann Surg (2018) 267:504-13. doi: $10.1097 /$ SLA. 0000000000002116

38. Fridman WH, Zitvogel L, Sautès-Fridman C, Kroemer G. The immune contexture in cancer prognosis and treatment. Nat Rev Clin Oncol (2017) 14:717. doi: 10.1038/nrclinonc.2017.101

39. Kalluri R. The biology and function of fibroblasts in cancer. Nat Rev Cancer (2016) 16:582-98. doi: 10.1038/nrc.2016.73

40. Mariathasan S, Turley SJ, Nickles D, Castiglioni A, Yuen K, Wang Y, et al. TGFbeta attenuates tumour response to PD-L1 blockade by contributing to exclusion of T cells. Nature (2018) 554(7693):544-8. doi: 10.1038/nature25501

\section{Conflict of Interest: JZ is an employee of Shanghai 3D Medicines Inc.}

The remaining authors declare that the research was conducted in the absence of any commercial or financial relationships that could be construed as a potential conflict of interest.

Copyright (c) 2021 Lv, Zhang, Sun, Nie, Chen, Wang, Xu, Wang, Liu and Chen. This is an open-access article distributed under the terms of the Creative Commons Attribution License (CC BY). The use, distribution or reproduction in other forums is permitted, provided the original author(s) and the copyright owner(s) are credited and that the original publication in this journal is cited, in accordance with accepted academic practice. No use, distribution or reproduction is permitted which does not comply with these terms. 